\title{
Care-less spaces and identity construction: transition to secondary school for disabled children
}

Dr Eleni Lithari

School of Education

Anglia Ruskin University

Chelmsford

UK

\section{Dr Chrissie Rogers}

School of Languages and Social Sciences

Aston University

Birmingham

UK

\begin{abstract}
There is a growing body of literature which marks out a feminist ethics of care and it is within this framework we understand transitions from primary to secondary school education can be challenging and care-less, especially for disabled children. By exploring the narratives of parents and professionals we investigate transitions and self-identity, as a meaningful transition depends on the care-full spaces pupils inhabit. These education narratives are all in the context of privileging academic attainment and a culture of testing and examinations. Parents and professionals, as well as children are also surveyed. Until there are care-full education processes, marginalisation will remain, impacting on disabled children's transition to secondary school and healthy identity construction. Moreover, if educational challenges not addressed, their life chances are increasingly limited. Interdependent caring work enables engagement in a meaningful education and positive identity formation. In school and at home, care-full spaces are key in this process.
\end{abstract}

\section{Introduction}

There is a growing body of literature which marks out and endorses a feminist ethics of care (e.g. Mahon and Robinson 2011, Held 2006), and it is within this framework we understand that transition from primary to secondary school education (moving from year 6 to 7) can be challenging and care-less, especially for disabled children and their families (Goodley and Runswick-Cole 2015, Holt 2004a, West, Sweeting and Young 2008). By interrogating narratives of parents and professionals, we are able to explore transitions and self-identity in multifarious ways, as arguably a meaningful transition depends on the care-full spaces disabled pupils inhabit, and those 'doing' caring work have a significant part to play (Pyer et al. 2010). Vis-à-vis space and place, Humphrey (2003) suggests classrooms ought to be accepting spaces where disabled children are equally included, academically and socially. Yet this is in the context of privileging academic attainment and a culture of testing and examinations (Slee 2011). In turn parents, (more often mothers), (Loukisas and Papoudi 2016, Rogers 2007, 2011) and professionals, are surveyed. Until there is meaningful inclusion, marginalisation will remain an experiential reality, for disabled young people, (Goodfellow 2012), impacting on their transition to secondary school, identity construction and disability performance (Holt 2010). Moreover, disabled children do not seem to have the same value as non-disabled 
children as normality presides, leading to a disabling world that marginalises and excludes (Goodley et al. 2015).

In England and Wales there are at least 220,000 children who have statements of 'special educational needs and disabilities' (SEN-D), while 16.0\% of children identified with 'special educational needs' (SEN) do not have a statement (DfE 2013). Between 2014 and 2018, education, health and care (EHC) plans/assessments replace the statement of SEN for children and young people up to the age of 25, depending on their circumstances (DfE 2015). In this paper we are responding to the assessment processes that have occurred prior to these changes. That said, for over three decades, policy directives have stated that parents and professionals ought to work together in partnership (and arguably in a care-full manner) and all disabled children ought to be included in mainstreams schools. This narrative has not changed, and neither has the challenging experiences that impact all involved, particularly for disabled children and their families (Rogers, 2011).

The statement of SEN and the EHC plan, as official documents, identify and pathologise children's additional educational, and sometimes pastoral/health requirements in an attempt to make them 'fit' within the expected norms of the school environment. The statement of SEN, (and the EHC plan) is also a collection of 'expert' comments that often include, teachers, the SEN co-ordinator (SENco), educational psychologists, physiotherapist, other health professionals, and parental views or assessments of/on the child. The premise of these documents and assessments are to enable support, yet many parents find the whole process of intense surveillance an exercise in apportioning blame, and one which is extremely care-less (Busswell Griffiths et al. 2004, Rogers 2007). Yet without this (spurious) document, according to parents and professionals, transition to secondary school, can be psycho-socially damaging, as huge environmental changes (as well as emotional ones) occur. For the purposes of this paper, we identify families and their social networks, and health, social, and education professionals are all affected by the issues outlined, emphasising the contemporary magnitude of inhabiting care-less spaces. Furthermore, during challenging periods such as transition phases, disabled children can develop a 'spoiled' identity leading to limited life chances.

\section{Care-less spaces and a care ethics model}

Recently, a care ethics model of disability has been developed in response to the continued dehumanisation of intellectually disabled people (Rogers 2016). It is within this theoretical context, and in engaging with qualitative narratives, we explore care-less spaces and 'spoiled' identities. Largely because an 'ethics of care that is political and critical must be grounded in the concrete activities of real people in the context of social relations. In turn, these webs are affected by politics and the structure of social policies' (Mahon and Robinson, 2011: 2). In this case, these are parents and professionals in talking about their concrete activities and social relations regarding difficulties in learning for their children or those they work with. Moreover, school life, inside and outside of the classroom is influenced by the macro and micro politics of education that are currently driven by a business model of learning, as schooling, like education more broadly, is increasingly restrictive, bounded and often lacks creative opportunities (Slee 2011). This does not promote care-full learning or enable caring relations. 
The care ethics model of disability (Rogers 2016: 2) proposes three spheres of caring and carefull work, but these are currently populated with many care-less spaces.

\section{- $\quad$ The Emotional Caring Sphere}

o where love and care are psycho-socially questioned

\section{- $\quad$ The Practical Caring Sphere}

o where day to day care is carried out relationally

\section{- The Socio-political Caring Sphere}

o where social intolerance and aversion to difficult differences are played out

These three spheres all interact in complex ways and are grounded in social and political relations that seek caring legal and cultural processes (Rogers 2016). At the very least we need to challenge socio-political actions and processes within the education system that trouble us (Gillies 2012, Gillies 2016). Therefore, a care ethics model of disability is 'not about individual rights and freedom, as this detracts from the politics of care and leads us to a paternalistic state of doing and being, where those who are considered more vulnerable, frail and dependent are placed in a powerless position' (Rogers 2016: 34), but, that it is about human flourishing and social relations.

Furthermore, in the case of disabled children, and their identity development, how we imagine, understand, map and practice caring is important, as caring 'is not a strange activity which is undertaken by a few brave souls, but it is ingrained into the existence of every person' (Herring, 2013: 45). Care-less spaces are pervasive, yet powerful relations can be an incredibly positive source of carefulness in developing a healthy identity. The domains where power exists are within the institution (roles, rules, status), which is often discussed, but also within, or of the person (emotions, memories) (see Lucey and Rogers 2007). This understanding of power can be realised within a care ethics model of disability as the institutional and the emotional impact, in a relational way, upon the practices carried out day-to-day within schools, formally and informally. However, power is also more often used in a way that limits agency, and rather than promoting an interdependence (a freedom from dependence), it maintains dependence and limits choices in a care-less manner.

Rather than continued over assessment, a change in teaching methods practically and culturally could prove significant for children with SEN-D. Arguably, caring work should suit all individuals as pre-determined assumptions can lead to unnecessary labelling. Humphrey (2002) found that difficulties in self-development for dyslexic children for example, largely depend on individual experiences, types of difficulty and educational placements. In fact, Singer (2007) proposes the need to protect children's self-esteem in order to overcome their academic difficulties, largely because her participants highlighted the importance of support from parents and teachers (see also Lithari, 2014). For a meaningful transition, young people need to maintain their enthusiasm for learning, be confident, and have a sense of achievement 
and purpose (Demetriou et al. 2000), since students who are engaged in their learning experience are more successful than those who are not (Wang and Holcombe 2010).

Schooling has a central role in children's lives and ought to provide a supportive environment with positive ethos that is vital for all children (Holt 2004a, Russell 2003). Besides, it is universally agreed that children deserve to be educated in a way that enables them to reach their full potential and flourish (Koshy and Pinheiro-Torres 2013). Therefore, meaningful caring work is essential for children who find the current rigid education system difficult. Caring work is also important outside the school gates. Care lack can paralyse parents, rendering them 'disabled' both emotionally and practically (Buswell Griffiths 2004, Rogers 2007, 2013). Crucially relationships between families and professionals should not be about individualistic notions based on particular professionals; indeed, there should be a 'politics of recognition', and moreover that recognition is 'central component of social justice' (McLaughlin et al. 2008, 190). The promotion of social justice and care-full relations seem tantamount to flourishing educational experiences across all the caring spheres.

Care-less spaces, where a lack of care within an educational environment is problematic (Gillies and Robinson 2013, Gillies, 2016) and transition through momentous milestones during children's education, can have a significantly negative impact upon identity formation. This care-less-ness can be a result of formal and informal practices (with family or education professionals), particularly noticeable through difficult transitions. The main focus here is how parents offer and experience caring within the UK, because their experiences impact children's everyday lives. Furthermore, relationships with teachers, peers and family members are key to children's educational development (Luff 2013). These significant others interact with them and can influence children and young people's social identity construction. Besides, according to the SEN-D Code of Practice (CoP), teaching children identified with SEN is the responsibility of not only the whole school, but also the wider health providers (DfE 2015), yet this responsibility and caring work is often found to be left predominantly to family members. Some parents for example, through the assessment process, realise that without a diagnosis of a SEN their child is unlikely to gain additional support. This frequently leaves parents doing the formal and informal caring while they go through this trying period (Rogers 2011, 2013). Indeed, there are a wealth of policies in the UK around SEN provision that govern and impact upon key stakeholders, often education professionals, pupils and their families. Still policy and directives written, discuss in detail the care and education of disabled children, (DfE 2015), yet narratives about care-less spaces and care lack continue.

Socially and geographically significant here is the recognition of history and biography when writing about such issues laid out above, such as identity and care-less spaces. For as we see, Wright Mills suggested, 'the life of an individual nor the history of society cannot be understood without understanding both' (1959, 3). In our research, participants talk about their lives around mothering, parenting, caring, or SEN-D. It was always our aim to bring together these personal narratives in analysing discourses about parents and education professional's experiences of care practices and care-less spaces, as well as conflict within school settings. Therefore, we would like to propose caring and care-full practices in nurturing relationships and recognise the humanity in a care ethics model as care-less-ness in the form of oppression 
and inequality is dehumanising. Care-full and caring relations are a part of the philosophical foundations of a care ethics model. Care lack and bureaucratic systems hinder creativity and flourishing, and systemic tools to measure worth encourage educational conflict. Thinking therefore about care and care-less spaces more broadly

Prospects of human progress and flourishing hinge fundamentally on the care that those needing it receive, and that the ethics of care stresses the moral force of the responsibility to respond to the needs of the dependent [...] Moralities built on the image of the independent, autonomous, rational individual largely overlook the reality of human dependence and the morality for which it calls (Held 2006, 10).

\section{Researching care-less spaces}

Geographers recognise children as social actors (Holloway 2014) in a society where they are relatively powerless (Holt 2004b). Furthermore, research within children's geographies about disability, the ethical processes and lived experiences has come to the fore in the past decade or so (Curran and Runswick Cole 2014, Holt 2004a, 2010, Rogers and Ludhra 2012). That said, hearing children speak about their lives has been evident for a very long time. For example, Roberts (2008) tells us of child paupers reporting stories about their emigration to Canada in the $19^{\text {th }}$ Century. More recently, we have heard stories about and with disabled children and their educational environment, especially in relation to inclusion (Goodley et al. 2015, Smyth 2010), as well as hearing the voices of parents speaking in response to their disabled children's education (Hodge and Runswick-Cole 2008, Ryan and Runswick-Cole 2008). Negative experiences can stem from how difference is handled at school (Connors and Stalker 2007), which is a strong theme within both our studies discussed.

Although children are vital in understanding their own narratives, we have chosen to focus on parental and teacher voices as a way to access and understand caring practices, and engagement with children. Largely because, as a group of actors, they have such an impact upon disabled children's lives. These voices are important indicators in positioning care and care-less spaces and all the difficulties experienced, in their efforts to effectively support children. As it is, parental and professional caring came out as a very significant indicator of positive educational experiences and/or outcomes for the children. Support and care ranged from emotional care work, to 'battling' the school bureaucracies, and actively teaching their child themselves or employing tutors to supplement their education. These caring practices are significant and affect whole families and professional lives, making an important contribution to the experiences of children. With parental narratives, care work was necessary at home, often as a result of care lack at school. The education professionals' narratives add depth to this discourse, since they explain their view of the complicated relationships between parents and professionals in their efforts to care for/with the children; even though they do that in different ways and through different responsibilities.

One study examined conflict and contradiction within education via parental narratives for children identified with SEN-D and further looked into care ethics and policy analysis more 
recently (Rogers 2007, 2011, 2013a, b, 2016) and the other explored the impact of transitions and support on young dyslexic people's identity construction (Lithari 2014). Rogers (2007) carried out in-depth interviews with parents, mostly mothers, who had children identified with SEN-D and education professionals. She carried out 32 unstructured qualitative interviews. 13 of the parents were interviewed once and their interviews ranged from one and a half to three hours. Six were interviewed twice, two were interviewed three times and one was interviewed six times. She also interviewed 13 education professionals. This led to a large, in-depth data set. The interviews, whilst unstructured, followed a life cycle approach, which attempted to keep the process chronological and thematic. The research broadly found that mothers and fathers were angry, disappointed and despondent with the experience of education for their 'difficult to teach' children and crudely, the professionals found inclusion difficult in practice.

Lithari (2014) interviewed children and adults (both younger and older) with dyslexia about their experiences of transition from primary to secondary education. The children's parents were also interviewed about their experiences and the support they offered to their children. An education professional was also interviewed to add context to the data and to explain inclusion-related organisational issues. Each participant was interviewed once, leading to 20 in-depth interviews. Participants were recruited via multiple methods: some were asked to participate either by acquaintances of the researcher herself, while others responded to participant requests which were advertised in an SEN magazine and on-line. Participants had to be dyslexic; parents who made contact about their taking part were also offered the option to participate if they wanted to. For the purposes of this paper the data utilised is mainly from the parents and professionals from both data sets. Participants in both studies were interviewed using open-ended interview schedules. In addition, both studies analysed data using thematic analysis, yielding multiple themes as dictated by the data; those themes were further categorised into fewer major categories. Furthermore, both studies received institutional ethical approval and all names are pseudonyms. Importantly for this paper, both studies identify support and caring, or rather care lack as a key theme.

\section{SEN-D and care-full/care-less work}

This paper is largely based on engaging with a care ethics model of disability and parental experiences in relation to caring for and about children with SEN-D. The themes common in both our studies in relation to parent's narratives were institutional caring (and the lack of it, in other words, care-less spaces) and familial caring work (including hiring tutors, acquiring a label, working with/against education professionals). In part, both studies were about the process of assessment and statementing of children identified with SEN, and then interactions between parents and professionals involved. Some children in our research received a late diagnosis and therefore the identification of a SEN-D triggered a possible identification of a less visible condition, such as Asperger syndrome, or dyslexia. However this process is initiated, it is often challenging for parents emotionally and practically. This is essentially because the process of assessing a child's learning needs underlined what their child was unable to achieve, leading to a care-less process. Invariably nothing is fed back to parents about what 
the child achieved, because the assessment report is only produced in order to glean the child's educational (and sometimes social) needs from a deficit and pathologising perspective. This process is not only time consuming generally but also requires an inordinate amount of caring and emotional work from the parents (Rogers, 2013a).

During this assessment process, parents, especially the main one caring, (often the mother), generally wavered between feeling out of control (and yet wanting to be in control), to wanting someone else to take over (and care). Parents often need to feel in control of their child's future and yet want and need someone to care with and about them too (Rogers 2013a). Parents and education professionals involved here both had the same objectives (most of the time): to educate the child in a way best suited to their needs. But both came at this from a different perspective. Education professionals are doing a job, they have goals, whether to produce a report for an assessment or teach a class of thirty children with a multitude of educational needs. They often are guided by a framework of policy guidelines, directives, budgets or staffing remits. Parents conversely are only focused on their child. They are emotionally involved and may have already spent several years trying to understand their child's difficulties.

Parents are constantly led to believe that professionals involved in their child's life will actively seek their involvement (DfE 2015, Rogers 2011). However, we identify the relationship between parents and health/education professionals is fraught with conflict and tension. This seems to be based on the parents' emotional investment and caring work. Yet the professionals' working environment is structured in such a way, for example, constraints around time, financial restrictions and the allocation of provision, that conflict seems inevitable. Despite all the documentation on 'inclusive' education (Rogers 2013b; Slee 2011), we reveal that for many children identified with SEN-D, their parents find 'inclusive' education an abstract notion and part of a care-less rhetoric. Negotiating this process is so difficult for parents and children that many return to, or are placed within, specialist provision by the time they reach secondary school at the age of 11, so at the period of just beyond transition in England and Wales. While politicians and policy makers (DfES 1978, DfES 2004, 2015) claim that there should be parental/professional partnership, this is not experienced as a reality by parents. The contradictions that occur between experiences and policies are evident. Furthermore, the privileging of academic attainment and the 'normal' can exclude the child with SEN-D and their families from engaging in a so-called 'inclusive' society (Goodley, et al. 2015). Currently therefore parents and educational professionals continue to struggle with 'inclusion' versus 'academic excellence', a conflict which also impacts transitions for SEN-D children.

Our research reveals a mixture of experiences, where some schools offer high levels of carefull work while others are seemingly care-less. Moreover, this significantly shaped parent's experiences and relationships with the schools. For children identified with SEN-D, institutional care-full work can positively enhance self-identity construction. Trust worthy and respectful pupil-teacher relations at all levels are beneficial for meaningful pupil flourishing at school (Barder and Olsen 2004). For many pupils their academic attainment is critical for healthy sense of self, since it is privileged, while experiencing caring improves their selfesteem. But care-less spaces compound stigmatisation of pupils, largely because some disabled children are unable to conform to cultural norms (that of high educational attainment). 


\section{Care-less spaces}

In our research it is shown that lack of care can stem from a lack of specific training or careless bureaucratic management systems. Examples from Amy and Jo, education professionals in Chrissie's research, demonstrate this. Amy said she was aware of inadequate training, which confirms that even before considering the pupil in school, at a socio-political level, the caring work is missing: it is care-less as described here,

there were not any lessons specifically on differentiation [...]. I would have liked some formal input on the curriculum. I didn't really know what dyspraxia meant. I didn't really know what dyslexia meant and I still don't to be honest. Having taught for two years I can honestly say I haven't had the input that I need although I've asked for it.' [...] I'm actually the special needs liaison link person for my faculty!

This miss-match between inclusion and how teachers learn is evident, and will always impact negatively for children. Considering the privileging of educational attainment and how schooling plays a central role in children's lives, when specific training is not offered, or is inadequate, parents sometimes take matters into their own hands by hiring specialist tutors to help their child develop academically, or intervene in other ways. Jo, a mainstream teacher who is also the 'inclusion' officer, told Chrissie about a 12-year-old student that characterises careless 'management' of pupils who challenge the system during the first year of transition to secondary school:

I've got a girl (Tilly) in year 7 (aged 12) who is [pause] very aggressive, gets involved in a lot of trouble and there was a big fight after school last night, and it came across on the radio [two-way radio transmitter] 'any radio holders there's a fight out the front can any staff get round there', so I've gone running round there with assistant head of year $8,[\ldots$. I called Tilly back and she came back and I said 'look Tilly we aint chasing you lot round the borough', and I said 'what's going on?', and she said 'nothing's going on'. I said 'well something's going on, do you want to tell me what's going on', now the girls had come back and she's talking to me and then the head of year arrives, 'Oh it's you again is it?' Do you know what I mean! 'Get back to my office I'll deal with you', he shouted, and I thought hang on, you don’t even know if Tilly's done anything yet, so off she was marched and I crossed over the road and thought I'd smack that woman in the fucking mouth before long. I thought, you know, how are you going to turn a kid around unless you treat them with some respect, and alright maybe she (Tilly) was the main instigator, but well done for coming over when I called you and that would have been a perfect opportunity and in bowls this head of year, blah, blah, fucking get on with it. And that's what happens all the time.

This type of pastoral and care-full work is obvious, indeed demanding, where front line teachers are heavily emotionally and practically involved with students, over and above the official curriculum, yet it is embedded within a care-less space. 
Hellendoorn and Ruijssenaars (2000) found that most of their participants received less support and understanding in their secondary schools than they did in primary. But in Eleni's research there was little or no support or care practices across the age groups. Such a case was Emma's, who received no support or care-full work, because although she had great difficulty, especially with her spelling, she was able to perform above the level classified as 'severely underperforming'. Which meant no care work was forthcoming. Her mother, Jenna, did try to talk to teachers about it, but found only care-less spaces. Therefore, the only option was to work with Emma's difficulties at home. Jenna, as Emma's mother, was left to pursue a diagnosis. Importantly this meant that Jenna had to 'acquire' a diagnosis to secure support, exam concessions and receive care for her daughter as she explains here, 'Coz obviously you've got a limited amount of time, and she might need a bit of extra time. [...] I’m thinking about going in and having a check, just to make sure that she gets the best possible support she can, at [...] one of the most important times of her life really'. Jenna's point of view is reasonable since performing well in tests becomes more important in secondary education, especially as examinations for entry in higher education are essential. Some children may not be concerned with this issue, while their parents are. Christy, a mother of a dyslexic boy, was very critical about her son's school policy. She said that they did not care much about dyslexia, stating that he needed more help than the school was providing. According to Christy, this was especially significant with school tests, because he only received additional time in important tests, which reduced his overall scores and lowered his self-esteem, therefore having an impact upon is identity formation. However, as explained by Kimberly, a SENco, school officials often make such decisions based on financial implications; not because of a lack of care, but we would argue this is care-less nevertheless.

The previous CoP (DfES 2001) states that statements of SEN are not required for exam concessions to be offered to students with SEN-D. According to this, in Eleni's research Emma could receive exam concessions without requiring an official statement, however her school did not offer any support without one. Furthermore, education professionals can be dismissive of certain difficulties in learning and parents blamed for overreacting or causing their children's problems (Rogers 2007). This, in part, happened with Emma and Jenna. Therefore, the only available option was to seek outside evidence for Emma's learning difficulty privately, which is what other parents have done as identified in Chrissie's research and elsewhere, when they could not convince the school officials to arrange an assessment with an educational psychologist (see also Buswell Griffiths et al. 2004). This is problematic for parents who are financially insecure, and can potentially leave children who are the most vulnerable in a dangerous and care-less space. This is turn leaves the bulk of caring work to parents, who have to 'fight' with the schools to secure support (as discussed below), especially if they are unable pay for private assessments. Without support and caring, children can develop very negative self-perceptions and become overwhelmed by their difficulties, such as in the case of a stigmatised identity (Goffman 1990). Since care-full practices aid the construction of a healthy sense of self, care lack can significantly damage children's academic attainment and psychosocial identity. Resources are not always available; however consistent lack of them leads to potentially damaging social problems for many pupils. 


\section{Battling with professionals - parental caring}

Parents play a crucial role in their children's education (LaRocque et al. 2011). Appropriate parental care can be the most important for a young person's healthy self-identity and the most important source of care and support for children (Dale and Taylor 2001). This is especially valuable when institutional care-less-ness is evident. In some cases, parents are the only ones caring for their children and fighting for their wellbeing (Hellendoorn and Ruijssenaars 2000). When institutional caring is insufficient, parents take schooling into their home by offering the materials and tutors their children need (Buswell Griffiths et al. 2004). This is highlighted by parents in our research who desired a label (to promote action) and so would invariably, if financially able, pay for their child to have a diagnosis and tutor support, largely because according to Debbie, in Chrissie's research, 'No one would put a label on him, nobody will put you in a particular box and nobody gave him any help'. We can also see the financial card being played out here by Mary, in Eleni's research, 'I've also paid for a lady to come in and do extra with 'im, which he enjoys [...]. So it's just [pause] to give 'im a bit of a push, you know, a bit of a boost' And again by Lynne in Chrissie's data,

(The psychologist) just chatted to Kevin for about half an hour and said Asperger syndrome and wrote me a lovely report. [...] I suppose if you've got the money and you get the right person you are paying for that person to write the thing that you want them to write. But that's life.

Some parents go to extreme lengths to give support and provide a meaningful education, as suggested here in Chrissie's research. Trisha, a working class mother with moderate family income, was able to re-mortgage her house to pay school fees while she was in conflict with the local education authority (LEA) about a specialist out of county residential school. Support from tutors could be perceived as supplementing school lessons and caring work, or compensating for the absence of care (Reay, 1998).

Some parents in our research tried to acquire institutional support by battling with schools. Other research also described that parents had to constantly 'fight' with the school to acquire the support that their children needed (Duncan 2003; Russell 2003), a process which led to anger and frustration. Parents of children with SEN-D are generally dissatisfied with the support their children receive (Parsons et al. 2009) and the battle between parents and schools was also recognised by policy discourse as a problem to be addressed by the proposed education reforms of 2014 (DfE 2015). Yet it seems this is not a reality, as Howard, the father of a dyslexic girl in Eleni's research, tried to support her at home in a care-full space. His main approach was to guide her in helping herself when she faced difficulties and said, 'We try and help her to help herself, not the other way around. There's no point in doing her homework for [her]'. However, not all parents are able to provide caring work and guidance, since they may lack academic experience themselves (Koshy and Pinheiro-Torres 2013). And as demonstrated in Eleni's research when asked about the support offered, Christy (a mother), replied by saying 
that there are not enough hours in the day to do everything she had to do. Since she believed that the school was not doing enough to support her son, tutoring at home was a good solution.

This type of care-full work from parents is time consuming, a financial burden and can be overwhelming when dealing with different education professionals. As Una in Chrissie's research said, 'I have this ton weight with one hundred and twenty-three professionals, and that's what it is, [...] And if you've got a child with more than one disability you start over again, all these people you have to engage with'. Actually hiring tutors to offer at-home care and support was a step that helped children enormously, and was received well by both them and their parents. But clearly, not all parents can finance private tutors so the caring work offered by the education system remains vital and buying 'experts' is not a resolution that ought to be reinforced. Institutional caring is significant, but parents often rely on each other and their social contacts, to support their children.

\section{Diagnosis and a label - what's in it?}

Many parents are aware of the connection between diagnosis and resource provision (Dale and Taylor 2001), since a label can remove barriers to useful resources. This justifies parental efforts to obtain an official diagnosis and use the label to gain support for their child (Tomlinson 2012). However, this does not always mean that the interventions employed after a statement/assessment will be suitable to the child's needs (Lauchlan and Boyle 2007), or if any addition care-full work will be implemented. Tomlinson (2012) believes many parents pursue a diagnosis to access specialist services because of the nature of education in contemporary societies. Qualifications and entry to higher education are considered necessary for members to function in an economy which is grounded in knowledge acquisition. In their efforts to provide for their children, a number of participants in Chrissie's research used parent support groups. Those groups had many benefits; for example, information gathering about how to gain support.

\section{Parent support groups, care-full spaces}

Chrissie's research, showed this knowledge exchange and much needed information as Lynne said, 'I joined the Asperger group in [name] and spoke to other parents and they'd said if you want a specialist college you're going to have to start doing the research, so I did all that, and I found one I wanted'. Furthermore, Mary told Chrissie, 'so I had a support of people who had been there before me in similar circumstances and the autistic spectrum group in [name] is excellent. Excellent people, all the legal knowledge and I did get a lot of help there'. However, many families with disabled children, may not belong, or choose not to belong to support groups, as revealed here by Trinny, in Chrissie’s research,

I've had times when I've felt really down, yeah I went to a couple of sessions (support group) where I sat with people who'd got special needs wringing their hands and I thought this is not me. This makes me feel worse rather than [pause]. I've got a good support network in close friends. 
And in the same vein, Karen told Chrissie, 'There was this support group in [name], but it was so depressing, I only went once. I thought I'm not ever going there [pause] it was absolutely awful'. Importantly, parents often change their minds when they come to terms with a diagnosis, as one of the parents above revealed that she later ran her own parent support group. However, the support group and care-full space is not simply about resource and practical advice. Our research does suggest parents who have a disabled child need an outlet with others who have a common understanding. Part of this care-full work seemed to be the acquisition of a label, since it practically helped both the child and the parents in dealing with institutional support and home life.

\section{Acquiring a label}

Since Western societies are driven towards academic excellence, many parents work hard to secure a place in higher education for their children and eliminate their chances of academic failure. Obtaining institutional support can help children with SEN-D achieve that goal. Although a diagnosis means a label and labelling can lead to stigmatisation, (Goffman 1990; Riddick 2000), there are many parents who see it as positive. Importantly, a label can be the first step to directing parents towards support groups and agencies that can help their children and themselves (Buswell Griffiths et al. 2004), because although they want support, many parents do not know how to acquire it.

Both Howard and Jenna in Eleni's research initially wanted to avoid a dyslexia label for their child respectively, but changed their minds because of the care-less space they and their child inhabited. There are education professionals who view labelling as harmful, due to stigmatisation (Riddick 2000) or a fear of gaining a 'spoiled identity' (Goffman 1990) and parents often share similar views. However, the issue of support and care was more important, especially around transition, as Howard told Eleni:

This is the thing with the statement problems. When they go into high school, if your child hasn't got a statement whatsoever, they're basically [...] thrown to the wolves. They were given a couple of weeks of help to help them move on and then basically you get thrown into the classroom with no help and get on with it. [...] I was pressured into getting a statement because of that.

Conversely, Katya, a mother, believed that there was care-full communication at her son's school, with information about him sent home. She believed that if she wanted something the educational professionals would listen to her, but added that if they did not listen she would keep pushing them until they did. Katya said she could talk to the SENco and it would be dealt with, suggesting that not all partnerships are corrosive, and not all spaces, care-less.

\section{Partnership between parents and education professionals}

The partnership between parents and professionals is significant, especially when it comes to providing care-full support. Parents have stressed that relationships with the education professionals have often broken down, or became antagonistic rather than supportive and mutually understanding. Our data revealed that based on pre-conceived notions of children 
with other more severe impairments, parents were frightened that their child might assimilate socially inappropriate behaviour, drawing even greater attention to their differences and difficulties. However, in Chrissie's research most of the parents whose children received alternative education found it to be a positive experience for their child and therefore for themselves. Crucially though, whatever the outcome of the education placement, it seems the education process is emotionally and practically difficult, time consuming, and often care-less. And partnership, as suggested in the policy documents, can only occur if both parties accept responsibility in a caring manner for their part of the relationship, including parents. As it happens, this mainstream teacher from Chrissie's research revealed that she found dealing with parents very difficult.

he (the child) goes out once a week and I think what she (the mother), she was bypassing me and just phoning up the head teacher and now she talks directly to the SENco, because she's the sort of parent who needs to be involved at every single stage [pause] That came out totally wrong! Basically this woman is like one of those parents who believes that her son doesn’t do anything wrong, so I find her slightly difficult to work with, and that's just my lack of experience with parents.

And a head of a 'special education' school stressed,

I say to all parents that it's a partnership and therefore it needs to be an honest relationship. [...] But the parent needs to talk to me early on not 3 months after a child has had problems. I also have to judge when to tell them all the stuff that is going on [pause] for the parent, and me [pause] it's about emotional intelligence and it's very highly charged emotionally especially when the child's young. And often they think that if you work on it all early that everything's going to be all right and it aint!

Similarly, Kimberly, a SENco, from Eleni's research also stressed the importance of partnership in parental support. She believed in parents and school establishments working together to support children and told her,

Parents can be my worst nightmare or my best friend. We have some really sensible parents, who know how much support to give and when to step back and when to let the child take the consequences of their actions and how much to make them, you know, do things. But we have other parents, where [pause] they come in Year 7 (transition year) and they've got a reading age of say 7 and a half, and we say, 'well, you need to read with your child every day for 10 minutes'. And they don’t!'

It is clear that sometimes parents want to be involved in relational care-full work, but are dismissed, and that education professionals work in such a highly charged environments these end up being care-less spaces. Educational environments for both parents and professionals ought to encourage care-full interdependent work that is realistic. Even schools with good intentions, that strive to develop pupil's full potential, need support from parents and community because they cannot educate a child on their own (LaRocque et al. 2011). 
Eleni encountered parents who did work in partnership with schools in a care-full way. Howard was involved in the school. He acknowledged that the school was very good at supporting his daughter's difficulties and said, 'Everyone has a block, you know. So they will then find a way of helping her go past that'. Although he acknowledged their caring work, he did not accept all their suggestions, especially about her attending a 'special' school one day a week as 'A lot of children have been pushed along that line, but it's up to the parents themselves to say 'no'. We do have a right to say, 'no, you're not going to do that.' [...] if I don't feel it's right, sorry, it stops here'. This indicates that not all parents are comfortable with their children attending a 'special' school. Significantly, Howard felt that this type of school was good for certain types of disabled children, but not for his daughter, which is clear narrative in Chrissie's research too. Indeed, stigma is strongly linked with feelings of humiliation (Gray 1993) and attending a 'special' school can cause this for some children (Hellendoorn and Ruijssenaars 2000). Labels are strongly associated with negative associations, but clearly a label, or rather the process, can be part of a route that enables care-full spaces and health identity construction.

\section{Concluding comments}

Socio-political narratives via policy directives that privilege academic excellence and promote an examination culture, work against care-full practices and feed care-less spaces, where those who are not traditionally academically able exist. This in turn impacts upon how practically and emotionally we all engage with such everyday occurrences. Therefore, we need to establish caring and care-full practices where interdependence is privileged and caring workers (education professionals and family members, for example), are valued indiscriminately (see also Mahon and Robinson 2011). This could be challenging considering the socio-political sphere has such power. Care-full practices need to be considered when exploring disabled children, their education transitions and identity construction. As research suggests, care, particularly in early childhood education, is a crucial part of the learning process (Luff 2013). So considering care-full practices, rather than necessarily pedagogical process, aids the development of a meaningful education, especially during challenging periods such as transition from primary to secondary school. This is because disabled children can become detached from education in multiple ways; academically, socially and emotionally (Slee 2011).

Significantly for children, existing within care-less spaces, difficulties and dilemmas that 'typical' learners are able to overcome seem magnified, and negative experiences can become part of their psycho-social identity (Goffman 1990). Without care-full support, educational identities are fractured. Their academic experiences, based on comparisons with their peers lead them to make negative assumptions about their own identities. This is even more remarkable when transitioning into secondary education, where schooling becomes more challenging in many ways. Children with SEN-D have to meet the increased workload, conquer their difficulties and manage the transition, all at the same time, which contributes to their sense of self. A care-full transition depends on the interdependent support children experience throughout the process; from peers, parents, and teachers, in the form of institutional resources and services (Anderson et al., 2000). This transition, in addition to their identity construction 
and performance of such (Holt 2004a) has a huge impact upon choices made into adulthood. Chiefly because of the privileging of academic proficiency, which makes it notably challenging for disabled children.

Indeed, if children's difficulties are not significantly dealt with, their life chances are increasingly limited (in this current educational climate). Interdependent caring work, whether emotional, practical and/or political, enables engagement in a meaningful education, and positive identity formation can occur. In school and at home, care-full spaces are key in this process. Transition to secondary school can vary in terms of the care experienced, but attitudes from peers and expectations from teachers and parents remain important. Identity is influenced by those experiences and determines the educational path young people choose. This makes it evident and crucial for school settings to offer support that goes beyond government directives. With appropriate care-full work, education professionals and parents can assist children through challenges of school life, as a

care ethics model of disability by reconceptualising what education looks like would help to reorganise and reform caring spaces, as a way of challenging the individualistic model, in a way that the social model of disability does not. A care ethics model does not see intellectual capacity as deficit, and neither ought educational processes (Rogers, 2016: 60-61).

\section{Acknowledgements}

We would like to thank our anonymous reviewers for their really helpful comments on an earlier draft. We appreciate the time this takes and that it has made for a stronger paper. Most of all we would like to thank our participants from both research projects. It goes without saying they are at the core of our work.

\section{References}

Anderson, L. W., Jacobs, J., Schramm, S. and Splittgerber, F. 2000. School transitions: the beginning of the end or a new beginning? International journal of Educational Research, 33(4), p. 325-339.

Barder, B. K. and Olsen, J. A. 2004. Assessing the transitions to middle and high school. Journal of Adolescent Research, 19(3), p. 3-30.

Buswell Griffiths, C., Norwich, B., and Burden B., 2004. Parental agency, identity and knowledge: mothers of children with dyslexia, Oxford Review of Education, 30 (3) p. 417-433,

Connors, C. \& Stalker, K., 2007. Children's experiences of disability: pointers to a social model of childhood disability, Disability \& Society, 22(1), p. 19-33 
Curran, T. and Runswick-Cole, K. 2014. Disabled children's childhood studies: a distinct approach? Disability and Society 29 (10) 1617-1630.

Dale, M. and Taylor, B. 2001. How adult learners make sense of their dyslexia. Disability \& Society, 16 (7), p. 997 - 1008.

Demetriou, H., Goalen, P. and Rudduck, J. 2000. Academic performance, transfer, transition and friendship: listening to the student voice. International Journal of Educational Research, 33(4), pp. 425-441.

DES, 1978. 'Special Educational Needs Report of the Committee of Enquiry in the Education of Children and Young People’ London: Department of Education and Science.

DfE, 2015. Special education needs and disability code of practice: 0 to 25 years, London, Department for Education.

DfE. 2012. Support and aspiration: a new approach to special educational needs and disability progress and next steps. London: Department for Education

DfE. 2013. Special educational needs in England, January 2013. London: Department for Education.

DfES, 1978. Special educational needs: report of the committee of enquiry into the education of handicapped children and young people. London: HMSO.

DfES, 2001. Special educational needs code of practice (Reference DfES/581/2001

DfES, 2004. Every child matters: change for children. London: Department for Education and Skills.

Duncan, N., 2003. Awkward Customers? Parents and Provision for Special Educational Needs, Disability \& Society, 18(3), p. 341-356.

Gillies, V. 2012. “'Inclusion” through exclusion: A critical account of new behaviour management practices in schools' in Y. Taylor (ed.) Educational Diversity: The Subject of Difference and Different Subjects Houndmills, Palgrave Macmillan.

Gillies, V. 2016. Pushed to the Edge: Inclusion and Behaviour Support in Schools, Bristol, Policy Press.

Gillies, V. and Robinson, V. 2013 'At risk pupils and the 'caring' curriculum' in C, Rogers and S, Weller [eds.] Critical Approaches to Care: Understanding caring relations, identities and cultures. London, Routledge

Goffman, E. 1990. Stigma: Notes on the Management of Spoiled Identity. London: Penguin Books.

Goodfellow, A. 2012. Looking through the learning disability lens: inclusive education and the learning disability embodiment. Children's Geographies 10 (1) 67-81. 
Goodley, D. and Runswick-Cole, K. 2015. Critical psychologies or disability: boundaries, borders and bodies in the lives of disabled children Emotional and Behavioural Difficulties, 20 (1) p. 51-63.

Goodley, D. Runswick-Cole, K. \& Liddiard, K. 2015. The DisHuman child. Discourse: Studies in the Cultural Politics of Education, DOI: 10.1080/01596306.2015.1075731

Gray, D. E. 1993. Perceptions of stigma: the parents of autistic children. Sociology of Health \& Illness, 15(1), p. 102-120.

Held, V., 2006. The Ethics of Care: Personal, Political and Global Oxford, Oxford University Press.

Hellendoorn, J. and Ruijssenaars, W., 2000. Personal experiences and adjustment of Dutch adults with dyslexia. Remedial and Special Education, 21(4), p. 227-239.

Herring, J. (2013) Caring and the Law Oxford, Hart Publishing Ltd.

Hodge, N. and Runswick-Cole, K. 2008 'Problematising parent-professional partnerships in education’, Disability and Society 23 (6): 637-647.

Holloway, S. L., 2014. Changing children's geographies. Children's Geographies, 12(4), p. 377-392

Holt, 2004b. The 'voices' of children: de-centring empowering research relations. Children's Geographies, 2(1), p. 13-27

Holt, L. 2004a. Children with mind-body differences: performing disability in primary school classrooms. Children’s Geographies, 2 (2) p. 219-236.

Holt, L. 2010. Young people's embodied social capital and performing disability, Children's Geographies 8 (1) p. 25-37.

Humphrey, N. (2002) a. Teacher and pupil ratings of self-esteem in developmental dyslexia. British Journal of Special Education, 29(1), p. 29-36.

Humphrey, N. 2003. Facilitating a positive sense of self in pupils with dyslexia: the role of teachers and peers. Support for Learning, 18(3), p. 130-136.

Koshy, V. and Pinheiro-Torres, C. 2013. 'Are we being de-gifted, miss?' Primary school gifted and talented co-ordinators' responses to the gifted and talented education policy in England. British Educational Research Journal, 39 (6) p. 953-978

LaRocque, M., Kleiman, I. and Darling, S. M. 2011. Parental involvement: the missing link in school achievement. Preventing School Failure: Alternative Education for Children and Youth, 55(3), p. 115-122.

Lauchlan, F. and Boyle, C. 2007. Is the use of labels in special education helpful? Support for Learning, 22(1), p.36-42. 
Lithari, E., 2014. Young people and their identities: the case of dyslexia and transition to secondary education (Unpublished $\mathrm{PhD}$ thesis). Anglia Ruskin University, Chelmsford, United Kingdom.

Loukisas T. and Papoudi, D. 2016. Mothers' Experiences of Children in the Autistic Spectrum in Greece: Narratives of Development, Education and Disability Across their Blogs International Journal of Disability, Development and Education 63 (1) On-line

Lucey, H., and Rogers, C., (2007) 'Power and the unconscious in doctoral student-supervisor relationships”, in, V, Gillies and H, Lucey (eds.) Power, Knowledge and the Academy: The Institutional Is Political, Houndmills, Palgrave Macmillan

Luff, P. 2013. 'Reclaiming care in early childhood education and care' in C, Rogers and S, Weller [eds.] Critical Approaches to Care: Understanding caring relations, identities and cultures London, Routledge.

Mahon, R. and Robinson F. (eds). 2011. Feminist Ethics and Social Policy: Towards a New Global Political Economy of Care Canada, University of British Columbia Press.

McLaughlin, J. Goodley, D. Clavering, E. and Fisher, P. 2008. Families raising disabled children: enabling care and social justice Basingstoke, PALGRAVE MACMILLAN

Parsons, S., Lewis, A., Davison, I. Ellins, J. \& Robertson, C. 2009. Satisfaction with educational provision for children with SEN or disabilities: a national postal survey of the views of parents in Great Britain. Educational Review, 61(1), p. 19-47.

Pyer, M., Horton, J., Tucker, F., Ryan, S., and Kraftl, P. 2010. Children, young people and ‘disability': challenging children’s geographies? Children's Geographies 8 (1) p. 1-8.

Reay, D. 1998. 'Cultural reproduction: mothers' involvement in their children's primary schooling.' In: Grenfell, M. and James, D. Bourdieu and education: acts of practical theory. London: Falmer.

Riddick, B. 2000. An examination of the relationship between labelling and stigmatisation with special reference to dyslexia. Disability \& Society, 15(4), p. 653-667.

Robinson, F. 2011. The Ethics of Care: A feminist approach to human security, Philadelphia: Temple University Press

Rogers, C. 2007. Parenting and Inclusive Education: discovering difference, experiencing difficulty Houndmills, Palgrave Macmillan

Rogers, C. 2011. 'Mothering and intellectual disability: Partnership rhetoric?' British Journal of Sociology of Education 32(4): 563-581.

Rogers, C. 2013a 'Intellectual disability and mothering: An engagement with ethics of care and emotional work' in C. Rogers and S. Weller (eds.) Critical Approaches to Care: Understanding Caring Relations, Identities and Cultures London, Routledge. 
Rogers, C. 2013b. 'Inclusion, education and intellectual disability: A sociological engagement with Martha Nussbaum', International Journal of Inclusive Education 17(9): 988-1002.

Rogers, C. 2016. Intellectual Disability and Being Human: A Care Ethics Model London, Routledge

Rogers, C. and Ludhra, G. 2012. 'Research ethics: participation, social difference and informed consent' in Bradford and Cullen (eds.) Research and Research Methods for Youth Practitioners, London, Routledge.

Russell, P., 2003. 'Access and achievement or social exclusion?' Are the government's policies working for disabled children and their families? Children \& Society, 17(3), p. 215-225.

Ryan, S. and Runswick-Cole, K. 2008. 'Repositioning mothers: Mothers, disabled children and disability studies’, Disability and Society 23 (3): 199-210.

Ryan, S. and Runswick-Cole, K. 2009. 'From advocate to activist? Mapping the experiences of mothers of children on the autism spectrum', Journal of Applied Research in Intellectual Disabilities 22: 43-53.

Singer, E. 2007. Coping with academic failure, a study of Dutch children with dyslexia. Dyslexia, 14(4), p. 314-333

Slee, R. 2011. The Irregular School: Exclusion, Schooling and Inclusive Education, Oxon, Routledge

Smyth, J., B. Down, and P. McInerney. 2010. Hanging in with the kids' in tough times: Engagement in contexts of educational disadvantage in the relational school. New York: Peter Lang Publishing.

Tomlinson, S. 2012. The irresistible rise of the SEN industry. Oxford Review of Education, 38(3), p. 267-286

Wang, M. T. and Holcombe, R., 2010. Adolescents' perceptions of school environment, engagement, and academic attainment in middle school. American Educational Research Journal, 47(3), p. 633-662

West, P., Sweeting, H. and Young, R. 2008. Transition matters: pupils' experiences of the primary-secondary school transition in the west of Scotland and consequences for well-being and attainment. Research Papers in Education, 25(1), p. 1-29.

Wright Mills, C., 1959. The Sociological Imagination New York: Oxford University Press 